\title{
Direct strength method for cold-formed steel beams with non-uniform temperatures
}

DOI:

10.1680/jstbu.20.00084

\section{Document Version}

Accepted author manuscript

Link to publication record in Manchester Research Explorer

\section{Citation for published version (APA):}

Alabi-bello, M., Wang, Y., \& Su, M. (2020). Direct strength method for cold-formed steel beams with non-uniform temperatures. Institution of Civil Engineers. Proceedings. Structures and Buildings, 1-18.

https://doi.org/10.1680/jstbu.20.00084

\section{Published in:}

Institution of Civil Engineers. Proceedings. Structures and Buildings

\section{Citing this paper}

Please note that where the full-text provided on Manchester Research Explorer is the Author Accepted Manuscript or Proof version this may differ from the final Published version. If citing, it is advised that you check and use the publisher's definitive version.

\section{General rights}

Copyright and moral rights for the publications made accessible in the Research Explorer are retained by the authors and/or other copyright owners and it is a condition of accessing publications that users recognise and abide by the legal requirements associated with these rights.

\section{Takedown policy}

If you believe that this document breaches copyright please refer to the University of Manchester's Takedown Procedures [http://man.ac.uk/04Y6Bo] or contact uml.scholarlycommunications@manchester.ac.uk providing relevant details, so we can investigate your claim.

\section{OPEN ACCESS}


Alabi-Bello, M.A., Wang, Y.C. and Su, M.N., (2020) "Direct Strength Method for ColdFormed Steel Beams with Non-Uniform Temperatures", Proceedings of the Institution of Civil Engineers - Structures and Buildings, 2000084.

\section{Direct Strength Method for Cold-Formed Steel Beams with Non-Uniform Temperatures}

4 Author 1

- Mutiu Alabi-Bello

- Department of Mechanical, Aerospace and Civil Engineering, The University of Manchester, Manchester, United Kingdom

- 0000-0002-1178-407X

9 Author 2

- Yong Wang, BEng, PhD, CEng, FIStructE

- Department of Mechanical, Aerospace and Civil Engineering, The University of Manchester, Manchester, United Kingdom

- 0000-0003-3336-5578

Author 3

- Meini Su, BEng, PhD, MICE, CEng

- Department of Mechanical, Aerospace and Civil Engineering, The University of Manchester, Manchester, United Kingdom

- 0000-0001-5513-4338

Date of text: July 2020

\section{Full contact details of corresponding author.}

Prof. Yong Wang (BEng, PhD, CEng, FIStructE)

Professor of Structural and Fire Engineering

Department of Mechanical, Aerospace and Civil Engineering

University of Manchester

Email address: yong.wang@ manchester.ac.uk

Phone number: +44 (0) 1613068968

Total word count in main text: 5278

Number of figures: 31

Number of tables: 4 


\section{Abstract}

This paper presents the results of finite element simulations leading to the development of a design method using the Direct Strength Method (DSM) for transversely loaded thin-walled steel beams prone to local and distortional buckling failures at elevated temperatures.

The systematic and extensive numerical parametric study covers different dimensions of thinwalled steel sections, different temperature distributions in the steel cross-section, different steel grades, and different load ratios. The main findings are that DSM is a suitable method for thin-walled steel members with non-uniform elevated temperature distributions in the crosssection. Based on using the plastic moment capacity of the cross-section at elevated temperatures, the existing AISI (2016) DSM equations are sufficiently accurate for local buckling. For distortional buckling, a set of new DSM equations are proposed.

The proposed DSM equations are then used to derive partial safety factors for structural resistance for conditional probabilities of structural failure of $0.1,0.01$ and 0.001 after flashover.

\section{Keywords chosen from ICE Publishing list}

Beams and girders, Fire engineering, Risk and Probability analysis

99

0

1

62

3




\section{$71 \quad$ List of notations}

72 b cross-section flange width

73 d cross-section lip depth

74 E Young's modulus of steel

75 E $\mathrm{E}_{20} \quad$ Young's modulus of steel at ambient temperature

$76 \quad \mathrm{E}_{\mathrm{T}} \quad$ Young's modulus of steel at temperature, $\mathrm{T}$

$77 f_{y} \quad$ yield stress of steel

$78 f_{y, 20}$ yield stress at ambient temperature

$79 f_{y, T} \quad$ yield stress at temperature, $\mathrm{T}$

$80 \mathrm{~h} \quad$ cross-section depth

$81 M_{c r d} \quad$ critical elastic distortional buckling load

$82 M_{c r l} \quad$ critical elastic local buckling load

$83 M_{F E M}$ moment capacity from finite element modelling

$84 M_{n d}$ bending resistance for distortional buckling, based on DSM

$85 M_{n e}$ bending resistance for global buckling, based on DSM

$86 M_{n l}$ bending resistance for local buckling, based on DSM

$87 \quad M_{p} \quad$ plastic moment capacity of beam

$88 \quad M_{y} \quad$ first yield moment of beam

$89 \mathrm{t}$ cross-section thickness

$90 \mathrm{U}_{\mathrm{x}} \quad$ displacement in $\mathrm{x}$ direction

$91 \mathrm{U}_{\mathrm{y}} \quad$ displacement in y direction

$92 \mathrm{U}_{\mathrm{z}} \quad$ displacement in $\mathrm{z}$ direction

$93 \varepsilon \quad$ radiative emissivity

$94 \theta_{\mathrm{z}} \quad$ twist about $\mathrm{z}$ direction

$95 \lambda_{d} \quad$ distortional buckling slenderness

$96 \lambda_{l} \quad$ local buckling slenderness

$97 \mu \quad$ Poisson's ratio 
110 The use of CFS (cold-formed steel), thin-walled construction has grown owing to their numerous advantages including high strength to weight ratio, flexibility of manufacture, fast and easy construction as well as low handling and transportation costs (Hancock et al., 2001).

113 As structural members, in addition to their traditional use as purlins and in other secondary 114 structures such as panels and floor decking, there is now widespread use of thin-walled steel 115 sections as main loadbearing structural members such as in lightweight portal frames, studs, 116 columns and beams.

117 Fire safety is critical to thin-walled steel building structures. In particular, thin-walled steel sections are usually part of a panel system exposed to fire from one side. Therefore, while the inclusion of fire protection materials and interior insulations improve their thermal and structural performances, they result in non-uniform temperature distribution in the crosssection of thin-walled structures. Care must be taken in understanding the structural behaviour as a result of non-uniform mechanical property distribution in the cross section of thin-walled steel beams. Non-uniform temperature distributions not only introduce thermal bowing (Wang and Davies, 2000), they also result in shift of the centre of resistance.

125 Whilst there have been a large number of research studies to investigate the fundamental behaviour of thin-walled steel structures in fire and how to improve their fire resistance (e.g. Feng et al. (2003); Feng and Wang (2005); Kankanamge (2010); Kankanamge and Mahendran (2012); Baleshan (2012); Baleshan and Mahendran (2016); Laím et al. (2014); Cheng et al. (2015); Landesmann and Camotim (2016); Jatheeshan and Mahendran (2016); Wang et al. (2020)), design calculation methods for fire resistance of thin-walled steel structures are still rudimentary.

132 The effective width method (EWM) and the direct strength method (DSM) are two candidates 133 for consideration in the development of fire resistance design methods for thin-walled steel 
structures, as for ambient temperature design. As noted by (Schafer, 2002a), EWM has a number of shortcomings: it calculates the effective widths of the different elements of a thinwalled steel section element-by-element thus ignoring element interactions; also it becomes cumbersome for members with longitudinal stiffeners. To overcome these shortcomings, the direct strength method (DSM) has been developed (Hancock et al. (1994); Schafer and Peköz (1998a); Schafer (2002b)). DSM combines the elastic buckling load of the member and the yield resistance of the cross-section to calculate the member resistance (Schafer and Peköz, 1998a). Simple computer programs, such as Cornell University Finite Strip Method (CUFSM) by Schafer and Ádány (2006) can be used to calculate the elastic buckling load in which interelement interactions are considered. The direct strength method has now been incorporated into a number of design codes such as AISI (2016) and Australian code AS/NZS 4600 (SA, 2018).

145 For fire resistance design of thin-walled structures with non-uniform temperature distribution, 146 the advantages of DSM over EWM are more profound: there is no need in DSM to tackle the 147 difficult challenge of dealing with non-uniform mechanical properties in calculating effective 148 widths of different plate elements. In DSM, it is relatively straightforward to incorporate non149 uniform temperature distribution in the cross-section when calculating elastic buckling load 150 and plastic cross-section property.

151 Because of these advantages, DSM is now mainly pursued by researchers. Results of studies by Heva and Mahendran (2008), Ranawaka and Mahendran (2009), Gunalan et al. (2015) show 153 that except for a few cases, DSM is applicable to uniformly heated and axially compressed 154 thin-walled steel sections. Landesmann et al. (2019) have demonstrated that DSM is 155 reasonably accurate for axially compressed members undergoing distortional buckling failure with high slenderness. Shahbazian and Wang (2011a), Shahbazian and Wang (2011b),

157 Shahbazian and Wang (2012) developed DSM equations for calculating compression 158 resistance of thin-walled steel studs at high temperatures, allowing for some bending moment. 
159 The context of their research is the situation when a thin-walled steel stud under compression

160 is exposed to fire from one side. Therefore, additional bending moments are generated in the

161 member due to $P-\delta$ (caused by thermal bowing) effect and the effect of shift of centre of

162 resistance. The have proposed new DSM equations for different failure modes (local buckling,

163 distortional buckling, and global buckling) under different heating conditions (standard fire

164 exposure, parametric fire exposure).

165 In contrast, research studies to assess applicability of DSM to flexural members at elevated

166 temperatures are limited. Studies by Kankanamge (2010) and Landesmann and Camotim

167 (2016) are limited to global and distortional buckling failure modes under uniform bending at

168 uniform elevated temperatures. Even so, Landesmann and Camotim (2016) reported that DSM

169 could not predict the distortional buckling strength of uniformly heated thin-walled steel

170 sections under pure bending.

171 There is a clear need to develop fire resistance design methods for thin-walled steel members

172 under bending. DSM has many advantages compared to EWM. Therefore, the aim of the

173 present study is to investigate suitability of DSM for fire resistance design of thin-walled steel

174 members under bending with non-uniform heating in the cross-section.

175 This research is carried out by a systematic and comprehensive evaluation of numerical 176 parametric simulation results using the general finite element software ABAQUS (Abaqus, 177 2014). Transient state structural-thermal analysis is performed so that realistic temperature 178 profiles are used in simulations of structural response. Since ABAQUS is used for both heat 179 transfer modelling and structural analysis, it is necessary to demonstrate its validity.

\section{Numerical Heat Transfer Analysis}

181 This research considers the following three types of panel construction for validation of heat transfer analysis: 
1. Fire protection boards on both sides without internal insulation;

2. Fire protection boards on both sides with external insulation;

3. Fire protection boards on both sides with internal insulation.

To ensure accuracy of heat transfer modelling, relevant fire tests by others are simulated.

\subsection{Steel sections with fire protection on both sides without interior insulation}

Baleshan (2012) and Jatheeshan and Mahendran (2015) carried out fire tests on thin-walled steel sections with open channel and hollow flange channel sections respectively. The joist arrangements are shown in Figure 1. The thickness of each layer of gypsum plasterboard and plywood is $16 \mathrm{~mm}$ and $19 \mathrm{~mm}$ respectively. The section dimensions are: web depth $180 \mathrm{~mm}$, flange width $40 \mathrm{~mm}$, lip depth $15 \mathrm{~mm}$, thickness $1.15 \mathrm{~mm}$ for the tests of Baleshan (2012), and web depth $200 \mathrm{~mm}$, flange width $45 \mathrm{~mm}$, lip depth $15 \mathrm{~mm}$, thickness $1.6 \mathrm{~mm}$ for the tests of Jatheeshan and Mahendran (2015).

The present ABAQUS heat transfer model has the following main features:

1. Emissivity of 0.9 on both the ambient and fire sides as proposed by Keerthan and Mahendran (2012);

2. Convective heat coefficients $25 \mathrm{~W} / \mathrm{m}^{2} \mathrm{~K}$ and $10 \mathrm{~W} / \mathrm{m}^{2} \mathrm{~K}$ for the fire and ambient sides respectively by Keerthan and Mahendran (2012);

3. Cavity radiation $(\varepsilon=0.6)$ for voids between the steel sections;

4. Standard fire exposure;

5. At least two elements of type DC2D4 (4-node linear heat transfer quadrilateral element) each in the steel thickness direction;

6. 6 elements in the thickness direction and $20 \mathrm{~mm}$ mesh in the longitudinal direction for the plasterboard and plywood.

7. TIE constraint to account for heat transfer by conduction between components. 
208 For gypsum plasterboard, the proposals of Keerthan and Mahendran (2012), Rahmanian and 209 Wang (2012) and Jatheeshan and Mahendran (2016) are adopted for its specific heat capacity, 210 density and thermal conductivity respectively, as suggested by Alabi-Bello and Wang (2018) 211 and shown in Figure 2, Figure 3 and Figure 4.

212 The thermal properties of steel (density, specific heat capacity and thermal conductivity) are 213 according to EN 1993-1-2 (CEN, 2005).

214 For plywood, the thermal properties proposed by Jatheeshan and Mahendran (2016) are used. 215 The density and specific heat capacity values are $500 \mathrm{~kg} / \mathrm{m}^{3}$ and $1.5 \mathrm{~kJ} / \mathrm{kg}^{\circ} \mathrm{C}$ respectively. Figure 2165 shows the temperature dependent thermal conductivity of the material.

217 The results in Figure 6 indicate acceptable agreement between test and numerical simulation 218 results, in particular in the important stage after evaporation of water from plasterboard when 219 the exposed side steel temperatures are high. The differences between numerical modelling and 220 test results may be attributed to uncertainties in thermal properties of the fire protection materials (plasterboard), as encountered by a number of previous researchers such as Mehaffy et al. (1994), Sultan (1996), Thomas (1997), Rahmanian and Wang (2012) and Keerthan and 223 Mahendran (2012).

\subsection{Steel sections with fire protection on both sides with internal or external thermal} insulation

Baleshan (2012) and Jatheeshan and Mahendran (2015) carried out fire tests on thin-walled sections with external fire protection on both sides and external or internal insulation, as shown in Figure 7(a) and Figure 7(b). The same simulation parameters and material thermal properties for plasterboard as in the previous section were used to simulate these tests. 
For the rockwool insulation, the thermal properties described in Keerthan and Mahendran (2013) are used. The density and specific heat capacity values are $100 \mathrm{~kg} / \mathrm{m}^{3}$ and $0.84 \mathrm{~kJ} / \mathrm{kg}^{\circ} \mathrm{C}$ respectively while Figure 8 shows its temperature dependent thermal conductivity.

234 Figure 9 presents comparisons of results between the simulations and the tests of (Baleshan, 235 2012) and (Jatheeshan and Mahendran, 2015). Again, the simulation results can be considered acceptable.

237 Overall, the numerical simulation model can be considered acceptable for heat transfer analysis.

\section{Validation of numerical models for structural behaviour}

240 Prior to carrying out nonlinear analysis for structural behaviour at elevated temperatures, it is 241 necessary to determine the failure loads of the test CFS thin-walled flexural members at 242 ambient temperature.

\section{$243 \quad 3.1 \quad$ Comparison against ambient temperature tests for bending}

244 The tests of Baleshan (2012) was selected for comparison. Figure 10 shows a typical finite 245 element configuration for one of the test beams, and the following describes relevant test 246 conditions and simulation features.

Finite element mesh size

248 While retaining 4 elements each in the lips, a $5 \mathrm{~mm}$ mesh size is used for the flanges, the web 249 and in the longitudinal direction. Shell element S4R is used for all elements.

\section{Boundary conditions}

251 To simulate simple supports used in the tests, the nodes at both ends are restrained against 252 movement in the lateral directions $\left(\mathrm{U}_{\mathrm{x}}=\mathrm{U}_{\mathrm{y}}=0\right)$ and rotation about the longitudinal direction 
$253\left(\theta_{z}=0\right)$. At one end, the mid-web node is additionally restrained against movement in the 254 longitudinal direction $\left(\mathrm{U}_{\mathrm{z}}=0\right)$.

255 It was reported by Baleshan (2012) that the plasterboard/plywood provided sufficient lateral 256 and torsional restraint of the steel sections. To simulate the restraining effect of plasterboards 257 and plywood on the beam sections, the flange nodes are restrained against lateral displacement $258\left(\mathrm{U}_{\mathrm{x}}=0\right)$ and twist about the longitudinal direction $\left(\theta_{z}=0\right)$ at locations of $300 \mathrm{~mm}$ intervals along 259 the top flange and $200 \mathrm{~mm}$ intervals along the bottom flange nodes respectively. These 260 locations represent the screw points in the tests as reported by Baleshan (2012). The beam span 261 was $2.4 \mathrm{~m}$.

\section{Material properties}

263 The measured ambient temperature mechanical properties are used. Elastic-perfectly plastic 264 stress-strain curve is adopted. For the tests reported by Baleshan (2012), the yield stress is 612 $265 \mathrm{MPa}$ and the Young's modulus and Poisson's ratio are $210260 \mathrm{MPa}$ and 0.3 respectively.

\section{Loading}

267 Uniformly distributed load in the form of a total pressure load is applied on the compression 268 flange of the beam, in accordance with the reported test loading condition.

\section{Residual stresses}

Schafer et al. (2010) concluded that the effects of residual stress may be offset by the increased

271 yield stress in the corner regions (cold-work effects) of the section. Therefore, neither was 272 considered in this research. 
274 The magnitude of initial imperfection for the first local buckling mode is assumed to be $0.34 \mathrm{t}$

275 (where $\mathrm{t}$ is section thickness), which corresponds to the 50\% CDF (cumulative distribution 276 function) value as recommended by Schafer and Peköz (1998b). The buckling mode is 277 determined via elastic buckling analysis in ABAQUS.

278 Figure 11 compares moment-deflection curves between the finite element modelling and those 279 of the quoted researcher. The result in Figure 11 demonstrates good agreement.

\section{$280 \quad 3.2 \quad$ Comparison against fire test results}

281 Transient analysis is carried out as in the fire tests of Baleshan (2012). It involved using 2 282 static, general steps in ABAQUS:

i. Step1-Mechanical load applied incrementally up to the target value; and

ii. $\quad$ Step 2- Temperatures incrementally applied to the member until failure.

The mechanical load is $40 \%(9 \mathrm{kN})$ of the ambient temperature peak load. Figure 12 shows the configurations of the CFS sections.

287 To minimise the effects of any inaccuracy in heat transfer on modelling structural response, the reported test steel temperatures are used for validation of structural analysis. Figure 13 shows the recorded test temperature distributions for one of the channel sections.

Table 1 lists the elevated temperature mechanical properties (yield stress, fy and Young's

291 modulus, E) as proposed by Kankanamge and Mahendran (2011) and thermal expansion 292 according to Lie (1992).

293 Kankanamge and Mahendran (2011) fitted Ramberg-Osgood model (Ramberg and Osgood, 294 1943) equations to their measured stress-strain curves and these are shown in Figure 14 for tests of Baleshan (2012). 
296 Figure 15 compares the simulation results with the test results of Baleshan (2012) and the

297 simulation results of Baleshan and Mahendran (2016). The agreement is very good, especially

298 the numerical modelling results are very close to the simulation results of Baleshan and

299 Mahendran (2016).

300 Furthermore, Figure 16 confirms that the present simulation gives the failure mode as that of

301 Baleshan (2012).

302 Overall, the simulation model can be considered validated for modelling flexural behaviour of

303 CFS members at ambient temperature and in fire.

\section{Numerical parametric study and assessment of fire resistance design method}

\section{$305 \quad 4.1 \quad$ Simplification of steel temperature distribution}

306 Temperature distributions in the cross-sections of thin-walled steel sections exposed to fire

307 from one side are non-uniform and non-linear, as shown in Figure 17 for the fire tests of the

308 validation study in the previous section.

309 Inclusion of the exact non-uniform temperature distribution in subsequent structural-thermal

310 analysis is time consuming due to the need to transfer the non-uniform temperature results to

311 multiple lines of nodes along the flanges, the lips and the web. This section examines whether

312 it would be possible to use simplified temperature distributions in the thin-walled steel cross-

313 section.

314 This assessment is based on the numerical heat transfer analyses results of the same fire tests

315 of Baleshan (2012) as in the validation study of the previous section.

316 In the simplified temperature distribution for CFS sections with interior insulation, it is

317 assumed that the hot flange/lip have the same temperature (magnitude equal of that of the mid-

318 flange), the cold flange/lip have the same temperature (that of the mid-flange) and the

319 temperature distribution in the web is bilinear, intersecting at the position of interior insulation 
as shown in Figure 18(a). For CFS sections without insulation, the web temperature distribution is assumed to be linear as shown in Figure 18(b). In addition, uniform temperature distribution is assumed along the member length.

Figure 19 compares the simulation results between using the actual temperature distributions in ABAQUS modelling and those using the simplified temperature distributions for the same load ratio ( $80 \%$ of the ambient temperature load carrying capacity).

The two sets of results in each case are almost identical, confirming that it is acceptable to use the assumed simplified temperature distributions in Figure 18.

\subsection{Numerical parametric study results and assessment of direct strength method}

The parametric study investigates the effects of changing all design variables, including beam length, cross-section size and yield stress, to generate a comprehensive database for both buckling failure (local and distortional) modes. Table 2 summarises the parameters and their values. The steel grades of 275, 355 and 450 are nominal standard steel grades, and the steel yield stress value of $612 \mathrm{~N} / \mathrm{mm}^{2}$ was used in the tests of Baleshan (2012), with a Young's modulus (E) of $210 \mathrm{GPa}$ and Poisson's ratio $(\mu)$ of 0.3 . In addition to the parameters in Table 2 , for simulations at elevated temperatures, the load ratio ranges from 0.3 to 0.8 . The member lengths have been chosen to be sufficiently long in order to minimise the effect of shear due to transverse loading. Additionally, the selected sections in Table 2 were chosen so that the lowest critical buckling modes obtained from preliminary buckling analyses are the same as intended.

The non-uniform temperature distributions are for three possible configurations of thin-walled steel floor beams, as shown in Figure 20: no interior insulation in the cavity (Case 1), half insulated cavity (Case 2) and fully insulated cavity (Case 3). Case 3 is an addition to cases 1 and 2 of Baleshan (2012). The plasterboard and plywood are $16 \mathrm{~mm}$ thick while depth of interior insulation depends on section size. The steel section temperatures are generated by heat 
transfer modelling using the validated ABAQUS model, and then simplified, as explained in

345 the previous section. The parametric study also includes ambient temperature results which

346 will be used to compare the simulation results with existing ambient temperature DSM (AISI,

347 2016) equations for thin-walled beams.

348 For simulations at elevated temperatures, the elevated temperature mechanical properties (yield

349 stress, $\mathrm{f}_{\mathrm{y}}$ and Young's modulus, E) are as proposed by Kankanamge and Mahendran (2011).

350 This model is adopted because of its ability to take into consideration different grades of steel.

351 The coefficient of thermal expansion is according to Lie (1992). The Ramberg-Osgood model

352 of Kankanamge and Mahendran (2011) is used to prepare the ABAQUS input stress-plastic

353 strain data, with suitable modifications to allow for the initial linear proportion and strain

354 hardening.

355 The magnitude of initial imperfection for the local buckling mode is assumed to be $0.34 \mathrm{t}$ (where

$356 \mathrm{t}$ is the section thickness) and $0.94 \mathrm{t}$ for distortional buckling mode, as recommended by Schafer

357 and Peköz (1998b). The buckling mode is determined via elastic buckling analysis in

358 ABAQUS.

359 Transient state non-linear structural-thermal analysis is adopted to mimic the effects of fire on structures. In the analysis, the beam is incrementally loaded up to a target mechanical load value and then subsequently heated up (by increasing the beam temperatures) until failure.

\subsubsection{Assessment of DSM for local buckling of beams at ambient temperature}

Figure 21 shows typical ultimate failure mode at ambient temperature. The figure shows that the numerical simulation model failed in local buckling mode as intended.

365 Table 3 lists all the simulation results and Figure 22 presents all the simulation results for

366 ambient temperature, plotted to show ratio of beam bending resistance/cross-section plastic moment - beam slenderness relationship. To calculate the beam slenderness, the beam critical elastic buckling load is determined using ABAQUS. 
The results in Figure 22 indicate very good agreement of the simulation results with the existing DSM calculations of AISI (2016) for local buckling resistance based on using the cross-section

371 plastic moment capacity, with average DSM/simulation results of 0.985 and a standard

372 deviation of 0.042 . This further confirms validity of the numerical simulation model as well as 373 assumptions of initial imperfections.

374

375

376

377

378

379

380

381

382

383

384

\subsubsection{Assessment of DSM for local buckling of beams at non-uniform elevated temperatures}

Figure 23 compares failure modes of a typical beam with various non-uniform elevated temperature distributions. Due to temperature gradient, the neutral axis under bending moves towards the cooler flange. Since only the depth of the section above the neutral axis is in compression thus liable to local buckling, increasing temperature gradient of the section reduces the depth of local buckling, as shown in Figure 23.

In addition to the local buckling failure mode shown in the above figures, Figure 24 shows an additional failure mode characterised by web local buckling and flange distortion. This failure mode is associated with large temperature gradients (half web depth and full web depth interior insulation) at a low load ratio (0.3). This occurs when the lower flange temperature is very high and thus retaining very little resistance, forcing the neutral axis to move further towards the cooler flange.

When calculating elastic critical buckling loads at elevated temperatures, it was found that the critical buckling loads of beams with high thermal gradients (half insulation and full insulation) fluctuated between different load ratios with some values even higher than the critical buckling load at ambient temperature. This is attributed to the shift of centroid of modulus of elasticity of the cross-section under significant thermal gradient. 
Figure 25 plots beam local buckling resistance - slenderness relationship for all the nonuniform temperature cases, and compares the simulation results with the original AISI (2016) DSM equations using plastic moment capacity.

The results in Figure 25 indicate that it is still suitable to use DSM to calculate beam local buckling resistance with non-uniform temperature distribution in the cross-section because all the simulation results are within a reasonably narrow band.

Figure 25 suggests that the original AISI (2016) equations based on plastic moment capacity are suitable, giving DSM/simulation ratio result with average of 0.986 standard deviation of 0.106. Furthermore, results in Figure 25 show that some resistances are greater than the plastic moment capacity of the beams. This is attributed to some strain hardening effect beyond yield. Hence, for design purpose, the plastic moment capacity of the section should be considered as the ultimate capacity.

\subsubsection{Assessment of DSM for distortional buckling of beams at ambient temperature}

405 Figure 26 shows typical ultimate failure mode at ambient temperature. The figure shows that the numerical simulation models failed in distortional buckling mode as intended. Table 4 lists all the simulation results and Figure 27 presents all the simulation results for ambient temperature, plotted to show beam bending resistance/yield moment ratio - beam slenderness relationship. To calculate the beam slenderness, the beam critical elastic buckling load is determined using ABAQUS.

411 The results in Figure 27 indicate very good agreement between the simulation results with the existing AISI (2016) DSM calculations for distortional buckling resistance based on using the

413 elastic section capacity, with an average of DSM/simulation results of 0.990 and a standard

414 deviation of 0.034 . This further confirms validity of the numerical simulation model as well as assumptions of initial imperfection. The simulation results of bending resistance at low 
416 slenderness are slightly higher than 1 due to using the first yield bending moment capacity $\left(\mathrm{M}_{\mathrm{y}}\right)$

417 of the cross-section.

418 At non-uniform elevated temperatures, it is more convenient to use the plastic moment capacity 419 of the cross-section. Hence the results in Figure 27 are replotted in Figure 28 based on using 420 the plastic moment capacities of the beam cross-sections.

421 Obviously, the existing AISI (2016) DSM equations based on the plastic moment capacity of 422 cross-section overestimate the member resistance. To improve accuracy, it is necessary to 423 derive a set of modified equations for use with plastic moment capacity of the cross-section.

424 They are given in equations 1 and 2. Using the modified equations, the average of DSM 425 result/simulation result ratios is 1.005 and the standard deviation is 0.049 .

$$
M_{n d}=M_{p} \quad \text { for } \lambda_{d} \leq 0.4 \quad \text { Equation } 1
$$

427

$$
M_{n d}=\left[0.85-0.18\left(\frac{M_{c r d}}{M_{p}}\right)^{0.45}\right]\left(\frac{M_{c r d}}{M_{p}}\right)^{0.45} M_{p} \quad \text { for } \lambda_{d}>0.4 \quad \text { Equation 2 }
$$

\subsubsection{Assessment of DSM for distortional buckling of beams at non-uniform elevated} temperatures

430 Figure 29 compares failure modes of a typical beam at various non-uniform elevated temperatures. It could be seen that all the beams failed in distortional buckling mode.

432 The results in Figure 30 indicate that it is suitable to use DSM to calculate beam distortional 433 buckling resistance with non-uniform temperature distribution in the cross-section because all 434 the simulation results are within a reasonably narrow band. The results also suggest that the modified DSM equations (equations 1 and 2), are applicable giving mostly safe results. The average of modified DSM/simulation result ratios is 0.923 and the standard deviation is 0.081 .

437 As previously explained under local buckling, the results for FEM greater than $\mathrm{M}_{\mathrm{p}}$ are a result of strain hardening. 
440 According to Zhang et al. (2014), the probability of failure (P(f)) of a structure may be 441 expressed as follows:

$442 \mathrm{P}(\mathrm{f})=\mathrm{P}(\mathrm{f} /$ flashover $) \mathrm{P}($ flashover/fire occurring $) \mathrm{P}($ fire occurring $)$

Equation 3

443 Fire resistant design of structures is usually based on the assumption of flashover fire. The 444 probability of structural failure under flashover fire is expressed as follows:

$445 \mathrm{P}(\mathrm{f} /$ flashover $)=\mathrm{P}(\mathrm{f}) /\{\mathrm{P}($ flashover/fire occurring $) \mathrm{P}($ fire occurring $)\}$

Equation 4

446 If reliability of the structure under fire attack is the same as under ultimate limit state design of 447 the structure at ambient temperature, then the same reliability index of 3.8 should be achieved, 448 corresponding to an overall probability of structural failure of $7.23 \times 10^{-5}$. The values are based 449 on recommendations of CEN (2002) for general building design.

450 The probabilities $\mathrm{P}$ (flashover/fire occurring) and $\mathrm{P}$ (fire occurring) vary depending on many 451 factors. Accordingly, the acceptable level of $\mathrm{P}(\mathrm{f} / \mathrm{flashover})$ changes for the same overall 452 probability of structural failure of $7.23 \times 10^{-5}$. This implies that there is no single acceptable 453 value of the conditional probability $\mathrm{P}(\mathrm{f} / \mathrm{flashover})$.

454 Following Maraveas et al. (2017), partial safety factors for structural resistance are calculated 455 for the conditional probability $\mathrm{P}(\mathrm{f} / \mathrm{flashover})$ of $0.1,0.01$ and 0.001 respectively.

456 Figure 31(a) shows percentage distribution as a function of DSM calculation/simulation result 457 ratios for all members under local buckling with non-uniform heating, indicating a normal 458 distribution while Figure 31(b) shows that for distortional buckling mode. The overall average 459 of the ratios is 0.986 and the standard deviation is 0.106 . Using these values, the partial safety 460 factors for conditional probabilities $\mathrm{P}(\mathrm{f} / \mathrm{flashover}$ ) of $0.1,0.01$ and 0.001 can be calculated to 461 be $1.160,1.333$ and 1.498 respectively. 
462 A similar exercise was carried out for distortional buckling with non-uniform temperature 463 distribution in the cross-section. The partial safety factors for conditional probabilities $464 \mathrm{P}(\mathrm{f} / \mathrm{flashover})$ of $0.1,0.01$ and 0.001 can be calculated as $1.127,1.256$ and 1.372 respectively

\section{Conclusions}

466 This paper has presented the results of an extensive set of numerical parametric study to 467 investigate the behaviour and resistance of transversely loaded cold-formed thin-walled steel 468 beams at ambient and elevated temperatures with non-uniform temperature distributions. The 469 parameters covered different section sizes, slenderness, steel grades and load ratios. All the 470 steel members failed under local and distortional buckling modes as intended. The assessment 471 is based on simulation results generated using an ABAQUS model that was validated against 472 experimental test results for both heat transfer and structural analysis at elevated temperatures.

473 It has been found that a simplified temperature distribution can be used to represent the much more complex non-uniform temperature distribution in thin-walled sections exposed to fire 475 from one side. In the simplification for sections with interior insulation, it is assumed that on either the hot or cold side, the flange/lip temperatures are the same, while temperature

477 distribution in the web is bi-linear with the end temperatures equalling to the hot flange/lip and 478 cold flange/lip temperatures, intersected at the position of interior insulation. For sections 479 without insulation, a linear assumption is used in the web.

480 The numerical simulation results are used to assess applicability of the direct strength method 481 (DSM). The main findings of this study are:

482 Direct Strength Method for local buckling:

483 1. For steel beams at ambient temperature, the numerical load carrying capacities of the 484 beams agree well with calculation results using the existing AISI (2016) DSM equations, based on plastic moment capacity. 
2. For steel beams with non-uniformly distributed elevated temperature in the crosssection, the AISI (2016) equations based on plastic moment capacity can be used.

3. To achieve conditional probabilities of $\mathrm{P}(\mathrm{f} / \mathrm{flashover})$ of $0.1,0.01$ and 0.001 , the partial safety factors for structural resistance for non-uniformly heated members are 1.160, 1.333 and 1.498 respectively.

\section{Direct Strength Method for distortional buckling:}

4. For steel beams at ambient temperature, the numerical load carrying capacities of the beams agree well with calculation results using the existing AISI (2016) DSM equations. However, if the AISI (2016) DSM equations are applied using plastic moment capacity of the cross-section, the AISI (2016) DSM calculation results overestimate the simulation results. Since it is preferable to use plastic moment capacity, a set of modified DSM equations have been proposed.

5. For steel beams with non-uniformly distributed elevated temperature in the crosssection, the modified DSM equations in (4) are sufficiently accurate.

6. To achieve conditional probabilities of $\mathrm{P}(\mathrm{f} / \mathrm{flashover})$ of $0.1,0.01$ and 0.001 , the partial safety factors for structural resistance for non-uniformly heated members are 1.127, 1.256 and 1.372 respectively.

\section{Acknowledgements}

This research was funded by Petroleum Technology Development Fund (PTDF) of Nigeria.

\section{References}

Abaqus (2014). Abaqus Unified FEA v6.14-3 Documentation, Dassault Systèmes Simulia Corp.

AISI (2016). North American specification for the design of cold-formed steel structural members. American Iron and Steel Institute, Washington, DC, USA. 
510 Alabi-Bello, M.A. and Wang, Y.C. (2018). Direct strength method for calculating distortional buckling resistance of cold-formed thin-walled steel beams with non-uniform elevated temperatures. Proceedings of the 10th International Conference on Structures in Fire FireSERT, Ulster University, Belfast, UK.

Baleshan, B. (2012). Numerical and experimental studies of cold-formed steel floor systems under standard fire conditions. PhD Thesis, Queensland University of Technology, Australia.

Baleshan, B. and Mahendran, M. (2016). Numerical study of high strength LSF floor systems in fire. Thin-Walled Structures, 101, 85-99.

CEN (2002). Eurocode - Basis of Structural Design, European Committee for Standardization, Brussels.

CEN (2005). Eurocode 3: Design of Steel Structures - Part 1-2: General Rules -Structural Fire Design, European Standard, Brussels.

Cheng, S., Li, L.Y. and Kim, B. (2015). Buckling analysis of cold-formed steel channel-section beams at elevated temperatures. Journal of Constructional Steel Research, 104, 74-80.

Feng, M. and Wang, Y. C. (2005). An analysis of the structural behaviour of axially loaded full-scale cold-formed thin-walled steel structural panels tested under fire conditions. Thin-Walled Structures, 43(2), 291-332.

Feng, M., Wang, Y.C., and Davies J.M. (2003). Structural behaviour of cold-formed thinwalled short steel channel columns at elevated temperatures, Part 1: Experiments. ThinWalled Structures, 41(6), 543-570.

Gunalan, S., Heva, Y.B. and Mahendran, M. (2015). Local buckling Studies of cold-formed steel compression members at elevated temperatures. Journal of Constructional Steel Research, 108, 31-45. 
534 Hancock, G.J., Kwon, Y.B. and Bernard, E.S. (1994). Strength Design Curves for Thin-Walled

535

536

537

538

539

540

541

542

543

544

545

546

547

548

549

550

551

552

553

554

555

556

557

558

559 Sections Undergoing Distortional Buckling. Journal of Constructional Steel Research, 31 (2-3), 169-186.

Hancock, G.J., Murray, T.M. and Ellifritt, D.S. (2001). Cold-Formed Steel Structures to the AISI Specification. Marcel Dekker Incorporation, New York.

Heva, B. and Mahendran M. (2008). Local Buckling Tests of Cold-formed Steel Compression Members at Elevated Temperatures. Proceedings of the 5th International Conference on Thin-walled Structures - ICTWS. Innovations in Thin-walled Structures, Gold Coast, Australia.

Jatheeshan, V. and Mahendran, M. (2015). Experimental study of cold-formed steel floors made of hollow flange channel section joists under fire conditions. Journal of Structural Engineering, 142(2).

Jatheeshan, V. and Mahendran, M. (2016). Thermal performance of LSF floors made of hollow flange channel section joists under fire conditions. Fire Safety Journal, 84, 25-39.

Kankanamge, N.D. (2010). Structural Behaviour and Design of Cold-formed Steel Beams at Elevated Temperatures. $\mathrm{PhD}$ thesis, Queensland University of Technology.

Kankanamge, N.D. and Mahendran, M. (2011). Mechanical properties of cold-formed steels at elevated temperatures. Thin-Walled Structures, 49(1), 26-44.

Kankanamge, N.D. and Mahendran, M. (2012). Behaviour and design of cold-formed steel beams subject to lateral-torsional buckling at elevated temperatures. Thin Walled Structures, 61, 213-228.

Keerthan, P. and Mahendran, M. (2012). Numerical studies of gypsum plasterboard panels under standard fire conditions. Fire Safety Journal, 53, 105-119.

Keerthan, P. and Mahendran, M. (2013). Thermal performance of composite panels under fire conditions using numerical studies: Plasterboards, rockwool, glass fibre and cellulose insulations. Fire Technology, 49(2), 329-356. 
570

Laím, L., Rodrigues, J.P.C. and Silva, L.S.D. (2014). Experimental analysis on cold-formed steel beams subjected to fire. Thin-Walled Structures, 74, 104-117.

Landesmann, A. and Camotim, D. (2016). Distortional failure and DSM design of cold-formed steel lipped channel beams under elevated temperatures. Thin-Walled Structures, 98, 75-93.

Landesmann, A., Camotim, D. and Silva, F.C.M. (2019). DSM design of cold-formed steel columns failing in distortional modes at elevated temperatures. International Journal of Steel Structures, 19(3), 1023-1041.

Lie, T.T. (ed) (1992). Structural Fire Protection: Manual of Practice, ASCE Manual and Reports on Engineering Practice No.78, American Society of Civil Engineers, New York.

Maraveas, C., Wang, Y.C. and Swailes, T. (2017). Reliability based determination of material partial safety factors for cast iron beams in jack arched construction exposed to standard and natural fires. Fire Safety Journal, 90, 44-53.

Mehaffy, J.R., Cuerrier, P. and Carisse, G. (1994). A model for predicting heat transfer through gypsum-board/wood-stud walls exposed to fire. Fire and Materials, 18, 297-305.

Rahmanian, I. and Wang, Y.C. (2012). A combined experimental and numerical method for extracting temperature-dependent thermal conductivity of gypsum boards. Construction and Building Materials, 26, 707-722.

Ramberg, W. and Osgood, W.R. (1943). Description of stress-strain curves by three parameters. Technical Note No. 902, National Advisory Committee for Aeronautics, Washington DC.

Ranawaka, T. and Mahendran, M. (2009). Distortional buckling tests of cold-formed steel compression members at elevated temperatures. Journal of Constructional Steel Research, 65 (2), 249-259. 
585

586

587

588

589

590

591

592

593

594

595

596

597

598

599

600

601

602

603

604

605

606

607

SA (2018). Australia/New Zealand Standard, AS/NZS 4600, Cold-Formed Steel Structures. Sydney, Australia.

Schafer, B.W. (2002a). Progress on the Direct Strength Method. Sixteenth International Specialty Conference on Cold-Formed Steel Structures. Orlando, Florida USA.

Schafer, B.W. (2002b). Local, distortional, and Euler buckling in thin-walled columns. Journal of Structural Engineering, 128(3), 289-299.

Schafer, B.W. and Ádány, S. (2006). Buckling analysis of cold-formed steel members using CUFSM: conventional and constrained finite strip methods 18th International Specialty Conference on Cold-Formed Steel Structures. Orlando, Florida.

Schafer, B.W. and Peköz, T. (1998a). Direct strength prediction of cold-formed steel members using numerical elastic buckling solutions. Fourteenth International Specialty Conference on Cold-Formed Steel Structures. St. Louis, Missouri.

Schafer, B.W. and Peköz, T. (1998b). Computational modelling of cold-formed steel: characterizing geometric imperfections and residual stresses. Journal of Constructional Steel Research, 47, 193-210.

Schafer, B.W., Li, Z. and Moen, C.D. (2010). Computational modelling of cold-formed steel. Thin-Walled Structures, 48, 752-762.

Shahbazian, A. and Wang, Y.C. (2011a). Application of the Direct Strength Method to local buckling resistance of thin-walled steel members with non-uniform elevated temperatures under axial compression. Thin-Walled Structures, 49, 1573-1583.

Shahbazian, A. and Wang, Y.C. (2011b). Calculating the global buckling resistance of thinwalled steel members with uniform and non-uniform elevated temperatures under axial compression. Thin-Walled Structures, 49, 1415-1428. 
608

609

610

611

612

613

614

615

616

617

618

619

620

621

622

623

624

625

627

628

629

630

626 Figure 1. Floor joist arrangements with fire protection on both sides, (a) floor joist arrangement

Shahbazian, A. and Wang, Y.C. (2012). Direct Strength Method for calculating distortional buckling capacity of cold-formed thin-walled steel columns with uniform and nonuniform elevated temperatures. Thin-Walled Structures, 53, 188-199.

Sultan, M.A. (1996). A model for predicting the heat transfer through non-insulated unloaded steel-stud gypsum board wall assemblies exposed to fire. Fire Technology, 32, 239259.

Thomas, G.C. (1997). Fire Resistance of Light Timber Framed Walls and Floors, Fire Engineering Research Report 97/7, University of Canterbury, Christchurch, New Zealand.

Wang, Y.C. and Davies, J.M. (2000). Design of thin-walled steel channel columns in fire using Eurocode 3 Part 1.3. Proceedings of the 1st International Workshop on Structures in Fire, Copenhagen, Denmark, 181-193.

Wang, Y.C., Mahendran, M. and Shabhazian, A. (2020). Fire performance of thin-walled structures, CRC Focus Book, Taylor \& Francis.

Zhang, C., Li, G.Q. and Wang, Y.C. (2014). Probabilistic analysis of steel columns protected by intumescent coatings subjected to natural fires. Structural Safety, 50, 16-26.

Figure Captions using lipped channel sections, (b) floor joist arrangement using hollow flange sections

Figure 2. Specific heat capacity of gypsum plasterboard (Keerthan and Mahendran, 2012)

Figure 3. Density of gypsum plasterboard (Rahmanian and Wang, 2012)

Figure 4. Thermal conductivity of gypsum plasterboard (Jatheeshan and Mahendran, 2016) 
631 Figure 5. Thermal conductivity of plywood (Jatheeshan and Mahendran, 2016)

632 Figure 6. Comparison of steel temperature-time curves for floor configurations without 633 insulation, (a) comparison between test results of Baleshan (2012) and numerical heat transfer 634 modelling, (b) comparison between test results of Jatheeshan and Mahendran (2015) and 635 numerical heat transfer modelling

636 Figure 7. Floor joist arrangements with fire protection and insulation, (a) floor joist 637 arrangement using lipped channel sections with plasterboard and external insulation, (b) floor 638 joist arrangement using hollow flange channel sections with plasterboard and internal 639 insulation

640 Figure 8. Thermal conductivity of rockwool insulation (Keerthan and Mahendran, 2013)

641 Figure 9. Comparison of steel temperature-time curves for floor configurations with insulation

642 (a) comparison between test results of Baleshan (2012) and numerical heat transfer modelling,

643 (b) comparison between test results of Jatheeshan and Mahendran (2015) and numerical heat 644 transfer modelling

645 Figure 10. Typical finite element model for CFS flexural tests of Baleshan (2012)

646 Figure 11. Comparison between modelling results of Baleshan (2012) and the numerical 647 modelling results

648 Figure 12. CFS section configurations of fire tests of Baleshan (2012), (a) Test 1, (b) Test 2, 649 (c) Test 3

650 Figure 13. Recorded test temperature distributions for CFS channel sections of Baleshan 651 (2012), (a) Test 1, (b) Test 2, (c) Test 3 
652 Figure 14. Stress-strain curves of steel at different temperatures for the tests of Baleshan (2012)

653 Figure 15. Comparison between the numerical simulation, test results of Baleshan (2012) and 654 simulation results of Baleshan and Mahendran (2016) for CFS channel sections under bending 655 at elevated temperatures, (a) Test 1, (b) Test 2, (c) Test 3

656 Figure 16. Comparison between the numerical simulation failure mode and test result of 657 (Baleshan, 2012) for CFS lipped channel sections under bending at elevated temperatures, (a) 658 experimental test, (b) numerical model

659 Figure 17. Non-uniform temperature distribution in CFS channel section

660 Figure 18. Simplified temperature distributions, (a) with interior insulation, (b) without interior 661 insulation

662 Figure 19. Comparison of structural behaviour results between using assumed simplified and 663 actual simulated temperature distributions for two tests of Baleshan (2012), (a) Test 1, (b) Test 6642

665 Figure 20. Three possible configurations for generating temperature distributions in the steel 666 cross-section, (a) no interior insulation, (b) half interior insulation, (c) full interior insulation

667 Figure 21. Typical local buckling failure mode at ambient temperature

668 Figure 22. Beam local buckling resistance - slenderness relationships at ambient temperature

669 Figure 23. Typical local buckling failure modes at non-uniform elevated temperatures, (a) no 670 interior insulation, (b) half interior insulation, (c) full interior insulation 
671 Figure 24. Interaction of failure modes for 'half and full web depth interior insulation' 672 configuration under low load ratio, showing interaction between local web and flange 673 distortional buckling modes

674 Figure 25. Beam local buckling resistance - slenderness relationship at non-uniformly 675 distributed elevated temperatures, using plastic moment capacity as the basis

676 Figure 26. Typical distortional buckling failure mode at ambient temperature

677 Figure 27. Beam distortional buckling resistance - slenderness relationships at ambient 678 temperature

679 Figure 28. Beam distortional buckling resistance - slenderness relationships at ambient 680 temperature, using plastic moment capacity of cross-section

681 Figure 29. Typical distortional buckling failure modes at non-uniform elevated temperatures, 682 (a) no interior insulation, (b) half interior insulation, (c) full interior insulation

683 Figure 30. Comparison of beam distortional buckling resistance - slenderness relationships at 684 non-uniform elevated temperatures, using plastic moment capacity as the basis

685 Figure 31. Probability distributions for $\mathrm{M}_{\mathrm{n}} / \mathrm{M}_{\mathrm{FEM}}$ and $\mathrm{M}_{\mathrm{nd}} / \mathrm{M}_{\mathrm{FEM}}$ for transversely loaded beams 686 under local and distortional buckling at non-uniform elevated temperatures, (a) probability 687 density function of $\mathrm{M}_{\mathrm{n}} / \mathrm{M}_{\mathrm{FEM}}$, (b) probability density function of $\mathrm{M}_{\mathrm{nd}} / \mathrm{M}_{\mathrm{FEM}}$ 688 689 690 
693 Table Captions

694

695 Table 1. Mechanical properties and coefficient of thermal expansion at elevated temperatures

696 Table 2. Parameters for numerical study of beams with local and distortional buckling failure

697 modes

698 Table 3. Local buckling of transversely loaded cold-formed steel beams at ambient temperature

699 Table 4. Distortional buckling of transversely loaded cold-formed steel beams at ambient 700 temperature 